\title{
The determination of 3-methoxy 4-hydroxy mandelic acid in urine
}

\author{
A. J. WOIWOD AND R. KNIGHT \\ From The Wellcome Research Laboratories (Biological Division), Beckenham, Kent
}

SYNOPSIS A simple and accurate method for determining 3-methoxy 4-hydroxy mandelic acid $\underset{\dot{c}}{\vec{P}}$ in urine is described. The amounts excreted in urine in 24 hours by nine normal subjects and three $i$ patients with phaeochromocytoma have been determined.

The determination of 3-methoxy 4-hydroxy mandelic acid (vanillyl-mandelic acid) in urine is of importance in detecting the increased production of this major metabolite of adrenaline and noradrenaline in patients with phaeochromocytoma (Gitlow, Khassis, Cohen, and Mendlowitz, 1959) and also in investigations on hypertension in which there may be disturbance of catecholamine metabolism leading to increased excretion of vanillyl-mandelic acid (Studnitz, 1960). Various methods for estimating it in urine have been described (Armstrong, McMillan and Shaw, 1957; Studnitz and Hanson, 1959; Sandler and Ruthven, 1959; Gitlow et al., 1959; Robinson, Ratcliffe, and Smith, 1959), but none lends itself to rapid routine investigations with large numbers of urine samples. The method to be described is suitable for this purpose and can be carried out without recourse to special techniques such as paper chromatography, column chromatography, or high voltage electrophoresis. It is based on the fact that the azo dyestuff formed when vanillyl-mandelic acid is coupled with diazotized p-nitroaniline can be separated from interfering coloured substances by extraction from potassium carbonate solution into chloroform from which it can be re-extracted with sodium hydroxide to give a red solution suitable for colorimetry. In developing the method satisfactory conditions for selectively and quantitatively extracting vanillyl-mandelic acid from urine have been determined and the reaction between it and diazotized p-nitroaniline has also been studied in order to obtain maximum reproducibility.

\section{PROCEDURE}

REAGENTS In addition to ether A.R., chloroform B.P., and sodium chloride A.R. the following are made up:-

Received for publication 3 March 1961.
p-Nitroaniline reagent To $0.5 \mathrm{~g}$. p-nitroaniline add $\overparen{D}$ $3 \mathrm{ml}$. concentrated $\mathrm{HCl}$ and make up to $500 \mathrm{ml}$. with $\frac{\mathrm{C}_{\bar{D}}}{\overrightarrow{\mathrm{C}}}$ distilled water, any undissolved solid being filtered off. 3 This solution stores indefinitely. To prepare the reagent add 1 volume of $0.05 \%(w / v)$ sodium nitrite A.R. to $1^{-}$ volume of $\mathrm{p}$-nitroaniline solution, $\mathrm{mix}$ and leave two min. then add 1 volume of $0.025 \%(w / v)$ ammonium sulphamate to destroy traces of nitrous acid. Prepare the nitrite and sulphamate just before use. The reagent can be used for up to two hours after preparation.

Potassium carbonate solution A $10 \%(\mathrm{w} / \mathrm{v})$ solution of potassium carbonate A.R. in distilled water.

Standard vanillyl-mandelic acid solution Dissolve $10 \AA$ mg. DL-3 methoxy-4 hydroxy mandelic acid (Californian $\overrightarrow{\vec{A}}$ Corporation for Biochemical Research) in $100 \mathrm{ml}$. of distilled water. The solution can be stored at $-20^{\circ}$ for at least six months and can be kept safely for several weeks at $4^{\circ}$. Standards are prepared as required by appropriate dilution with distilled water.

Magnesium oxide ( for chromatography) Mix 1 part by weight of light magnesium oxide (May and Baker L 354) with 3 parts of cellulose powder (Whatman standardi grade), any small lumps of the oxide being broken up in a pestle and mortar or small mill before mixing with the cellulose.

Methanolic KOH Dissolve 0.1 g. KOH A.R. in 100 ml. methyl alcohol.

Sodium hydroxide $\mathrm{N} / 10$

\section{METHOD}

To $2 \mathrm{ml}$. of urine add $3 \mathrm{ml}$. of distilled water, $0.5 \mathrm{ml}$. of concentrated $\mathrm{HCl}$ and sufficient solid sodium chloride to saturate the solution and give a slight excess. Extract witle five successive $40 \mathrm{ml}$. volumes of ether, shaking well at⿱艹 each stage. Remove the extracted vanillyl-mandelic acid? from ether into aqueous solution by shaking the com=0 bined ether extracts with $25 \mathrm{ml}$. of distilled water cone taining sufficient $\mathrm{N} / 10 \mathrm{NaOH}$ (about $1 \mathrm{ml}$.) to give neutral extract followed by 15 and $10 \mathrm{ml}$. portions of distilled water. Develop colour by adding to the com bined aqueous extracts (which should be neutral to 


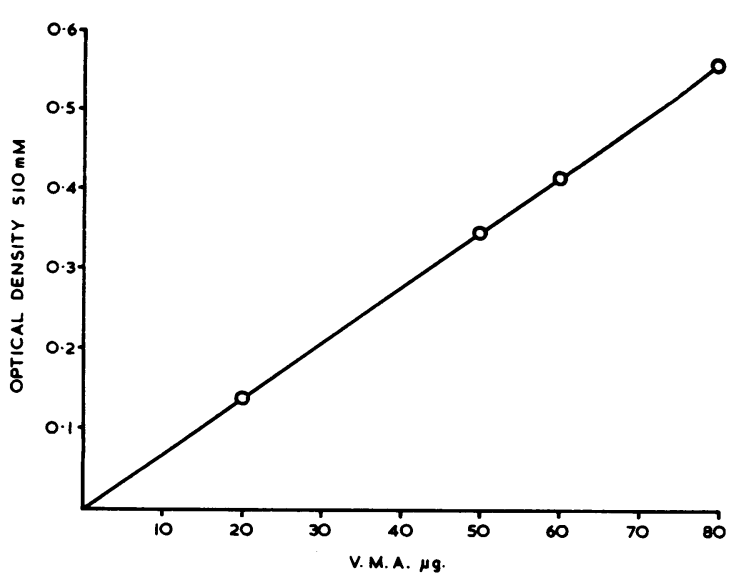

FIG. 1. Curve relating optical density of diazo-derivative of vanillyl-mandelic acid at $510 \mathrm{m \mu}$ to concentration of vanillyl-mandelic acid.

indicator paper) $5 \mathrm{ml}$. of p-nitroaniline reagent, leave for two min., then add $5 \mathrm{ml}$. of $10 \%$ potassium carbonate solution and leave a further five min. to allow maximum colour to develop. Remove the vanillyl-mandelic aciddiazo compound from the strongly coloured reaction mixture by shaking with successive 15,10 , and $5 \mathrm{ml}$. volumes of chloroform. The clear yellow chloroform solution obtained contains the un-ionized form of the complex. Extract into aqueous solution with 10, 5, 3, and $2 \mathrm{ml}$. of $\mathrm{N} / 10 \mathrm{NaOH}$, adjust the volume of the combined extracts to $20 \mathrm{ml}$., and read the resulting red solution in a spectrophotometer at $510 \mathrm{~m} \mu$. A small amount of coloured impurity is left behind in the chloroform layer after extraction with $\mathrm{NaOH}$. The spectrophotometer reading is converted into weight of vanillyl-mandelic acid by reference to a standard curve prepared with a solution of known vanillyl-mandelic acid using the same conditions for colour development as those used for the urine sample but omitting the ether extraction stage. A standard curve is shown in Fig. 1. The spectrophotometer used was a Unicam SP 600 using $1 \mathrm{~cm}$. cells.

The coupling reaction is very sensitive to light and it is therefore necessary to work out of direct sunlight and in subdued daylight or preferably artificial light to avoid losses and erratic recoveries. The chloroform extract of the vanillyl-mandelic acid complex is also unstable in the presence of light and the extraction with sodium hydroxide should therefore be carried out with the minimum of delay. The final red colour is stable for at least 24 hours.

Normally the separation of the chloroform layer in the final stage is rapid and complete but it may at times be necessary to give a short centrifugation before reading to remove suspended chloroform droplets. The colour of the test solution is occasionally slightly different in shade from that of the standard. This is due to an orange compound with an absorption maximum at $480 \mathrm{~m} \mu$ formed with some urines. Its formation is reduced to negligible proportions with the dilutions of urine extract and reagent used in the method. The vanillyl-mandelic acid complex may be freed from traces of this orange component by chromatography after acidifying the $\mathrm{NaOH}$ solution with $\mathrm{HCl}$ and extracting the resulting yellow colour into chloroform. The extracted material is adsorbed from the chloroform onto a column of magnesium oxide mixed with cellulose powder to aid solvent flow. The chromatogram is developed with methanolic $\mathrm{KOH}$, and the orange component, if present, moves down the column ahead of the red vanillyl-mandelic acid band, which can then be eluted separately. Using this method the vanillyl-mandelic acid-diazo derivative from $250 \mathrm{ml}$. of urine has been separated and shown to have an optical absorption curve identical with that obtained with known vanillyl-mandelic acid carried through the same procedure and a mixture of standard and urine derivatives could not be separated on a magnesium oxide column. The infra-red spectra of the two coloured materials have also been compared and are essentially the same, confirming that the method is determining vanillyl-mandelic acid without interference from the many other urine constituents which couple with the diazo reagent.

Studnitz (1960) considered ether and ethyl acetate equally satisfactory for extracting vanillyl-mandelic acid from urine. We find that ether has a greater selectivity against unwanted colour-forming substances and is therefore preferable, although as vanillyl-mandelic acid has a considerably lower distribution coefficient in ether/ water than in ethyl acetate/water fairly large volumes of solvent are needed for extraction. However, the bulk of the ether used is recovered for redistillation and further use. It is possible to remove the ether by distillation under reduced pressure but precautions must be taken to see that the ether used is completely free of peroxides as otherwise vanillyl-mandelic acid suffers considerable destruction. The extraction procedure avoids this difficulty besides taking less time.

\section{RESULTS}

The reproducibility of the coupling reaction and subsequent stages has been determined by analysis of 14 $50 \mu \mathrm{g}$. samples of standard vanillyl-mandelic acid solution. These were read at $510 \mathrm{~m} \mu$ in a $1 \mathrm{~cm}$. cell. The mean of the optical density readings was 0.348 with a standard deviation of $\pm 0.0063( \pm 1.81 \%)$. Recoveries of 20 and $30 \mu \mathrm{g}$. amounts of vanillylmandelic acid added to normal urine were $95.0 \%$ and $95.9 \%$ respectively. Complete extraction could be obtained only by increasing considerably the number of ether extractions and it is more convenient to use a factor of 1.05 to correct for this loss. This correction has been applied to the figures quoted in Tables I and II. Table I gives the total vanillylmandelic acid excreted in $24 \mathrm{hr}$. by a number of normal male subjects. Subjects $A$ and $B$ were medical students on balance experiments and therefore on a complete but controlled diet and 24-hr. 
TABLE I

EXCRETION OF VANILLYL-MANDELIC ACID BY NORMAL SUBJECTS

\begin{tabular}{rc} 
Subject & $\begin{array}{c}\text { Vanillyl-mandelic Acid Output } \\
\text { (mg./24 hr. })\end{array}$ \\
\hline A1 & $13 \cdot 3$ \\
2 & $11 \cdot 0$ \\
3 & $10 \cdot 6$ \\
B1 & $10 \cdot 0$ \\
2 & $10 \cdot 6$ \\
3 & $9 \cdot 0$ \\
C & $15 \cdot 0$ \\
D & 17.9 \\
E & $9 \cdot 0$ \\
F & 17.0 \\
G & 12.9 \\
H & $11 \cdot 1$ \\
I & 17.6
\end{tabular}

TABLE II

EXCRETION OF VANILLYL-MANDELIC ACID BY SUBJECTS WITH PHAEOCHROMOCYTOMA

\begin{tabular}{rcc} 
Subject & \multicolumn{2}{l}{ Output (mg./24 hr.) } \\
\cline { 2 - 3 } & New Method & Sandler and Ruthven Method \\
\hline $\mathrm{J} 1$ & 12.3 & - \\
2 & 16.7 & - \\
$\mathrm{K} 1$ & 14.8 & $12 \cdot 8$ \\
2 & 23.7 & $20 \cdot 0$ \\
$\mathrm{~L}$ & 25.6 & 27.5
\end{tabular}

urine samples on successive days were available and have been grouped in Table I. The other samples were from laboratory staff on unrestricted diets.
Table II shows pre-operative vanillyl-mandelic acid excretion figures for three proved cases of phaeochromocytoma, the urines being made available by the courtesy of Dr. M. Sandler. The two values given for subjects $\mathrm{J}$ and $\mathrm{K}$ were on urine samples obtained on different occasions. In the second column are the values supplied by Dr. Sandler for three of the urines using the method of Sandler and Ruthven (1959) as modified by Sandler and Ruthven (1960). Comparison of the two sets of figures shows reasonably good agreement between the two methods despite the very different techniques employed.

We thank Dr. M. Sandler for making available the phaeochromocytoma urine samples and for giving permission to quote his vanillyl-mandelic acid values for these urines. We also thank Dr. A. D. Munro-Faure for valuable discussion and for providing the urine samples from subjects A and B, and Dr. A. J. Everett for determining the infra-red spectra of the vanillyl-mandelic aciddiazo derivatives.

\section{REFERENCES}

Armstrong, M. D., McMillan, A., and Shaw, K. N. F. (1957). Biochim biophys. Acta, 25, 422.

Gitlow, S. E., Khassis, S., Cohen, G., and Mendlowitz, M. (1959). Clin. Res., 7, 237.

Robinson, R., Ratcliffe, J., and Smith, P. (1959). J. clin. Path., 12, 541 .

Sandler, M., and Ruthven, C. R. J. (1959). Lancet, 2, 114.

(1960). Proc. 4th International Congress of Clinical Chemistry.

Studnitz, W. von (1960). Scand. J. clin. Lab. Invest., 12, Suppl. 48, p. 36.

_, and Hanson, A. (1959). Ibid, 11, 101. 